\title{
SMEs, IT, and the Third Space: Colonization and Creativity in the Theatre Industry
}

\author{
Julie E. Kendall and Kenneth E. Kendall \\ Rutgers University, School of Business-Camden, USA
}

\begin{abstract}
We examine how small and medium-sized, professional, nonprofit performing arts theatres in the US can improve the strategic use of information technology (IT), as well as other aspects of theatre management for large, commercial theatre productions in the West End of London and on Broadway in New York City. In this article we use the epistemology of the third space developed by Bhabha (1994) and extended by Frenkel (2008). Although both authors were discussing knowledge transfer, we use their conceptualizations to characterize and explore more deeply the transfer process of culture (and thereby useful practices and worthwhile lessons) from small and medium-sized professional, nonprofit theaters to large-scale commercial theatres. We include a discussion of Nonaka's (1991) concept of ba, and how it relates to the third space. We specifically employ the metaphor of the third space developed by Bhabha (1994) to critique and understand the verbal and nonverbal cultural transmissions between small and large theatres. One of our contributions is to use the conceptualization and metaphor of the third space to understand the complex exchanges and relationships between small to medium-sized nonprofit professional theatres and large commercial theatres, and to identify what large commercial productions can learn from nonprofit theatres from these exchanges.
\end{abstract}

\section{Introduction}

Small nonprofit, professional theatres often struggle to live up to the creative, financial, marketing, IT, operational standards, and audience expectations of large, commercial productions ". Many times theatres denoted as "Off-Broadway," or "Off-Off-Broadway" are emblematic of the 1,800 or so small, professional, nonprofit performing arts organizations in the US, while the symbolic embodiment of the commercial heart of the theatre is widely acknowledged to reside in New York City's Broadway (Conte and Langley, 2007; Volz, 2004; \& Webb, 2004). In London, the symbolic commercial center of productions is the famed West End. In London, while the small and medium-sized professional theatre is called "The Fringe."

It is striking to note that small nonprofit theatres typically have as part of their mission the purpose of "transmitting culture," rather than the assimilation of culture, which

${ }^{1}$ We would like to thank the nonprofit theatre companies in New York City and Philadelphia for providing access to the administrative and artistic staff, actors, and directors as well as the producers of Broadway productions who enabled us to gather the knowledge and data for this paper. We would also like to thank The Drama League for its ongoing help and support. 
otherwise might be reasonably assumed due to their small production budgets and their geographic dispersion away from the cultural capitals of New York City and London. Since the inception of the nonprofit theatre movement in the US, there has been a noticeable flow and frequency of communication among the large-scale commercial productions and small local and regional nonprofit theatres. Local companies evidence this prominently in the movement of regional acting talent up from smaller venues to larger, mostly unionized commercial productions, for higher salaries, more notoriety and career exposure, and also via the licensing of copyright works for production.

Although communication, IT practices, and cultural content are often assumed to be trickling down from the large, commercial productions down to the small, nonprofit theatres, the actuality is far different. Small to medium sized nonprofit theatres can teach larger, commercial productions many lessons that can enhance and improve the strategic use of ICTs (information communication technologies), artistic expression, company creativity, financing, marketing, and operations of larger companies. Indeed, theatre researchers (Conte and Langley, 2007) note that in the last 30 years or so, commercial theatres have become increasingly dependent on original theatrical works (scripts and even productions) first developed regionally in nonprofit professional theatres. Often, these nonprofit organizations have as a primary goal the transmission of culture, via accomplishment of artistic and organizational goals, whereas the for-profit, commercial houses have the goal of becoming a financial success as their chief objective.

In this article we use the epistemology of the third space developed by Bhabha (1994) and extended by Frenkel (2008). Although both were discussing knowledge transfer, we use their conceptualizations to characterize and explore more deeply the transfer process of culture (and thereby useful practices and worthwhile lessons) from small and medium-sized professional, nonprofit theaters to large, for-profit commercial productions.

For the purposes of our study, it is possible to view the commercial theatre industry, symbolized by the Broadway houses, as the imperialist or colonialist power controlling the imagination of the audience and non-Broadway producers concerning what a good production is. Often the colonizing force has control of the labor, resources, and markets of those being colonized. As such, the imperialist power assumes it possesses superior culture, morals and values to those being colonized and is thus sanctioned to formally or informally enforce controls or set standards for the colonies. The language, culture, values, morals, laws and so on are all deemed to be flowing from the imperialist group to the colonists.

The colonialist's power may not even recognize or accept the principle of imposition. In fact the colonialist may see only the positive benefits of, for example, technology transfer. An example of this is the improved transportation systems, construction methods, disease prevention, and educational systems that the colonialist introduces to the colonies.

A colonial power receives (or even demands) certain benefits of being the colonial power. In world politics this could mean the exploitation of natural resources, or at its extreme, the enslavement of people. Although the consequences in the world of theatre may not be so severe, they are real. Some of the resources that large commercial productions take from the smaller nonprofit theatre companies are shown in Figure 1. 

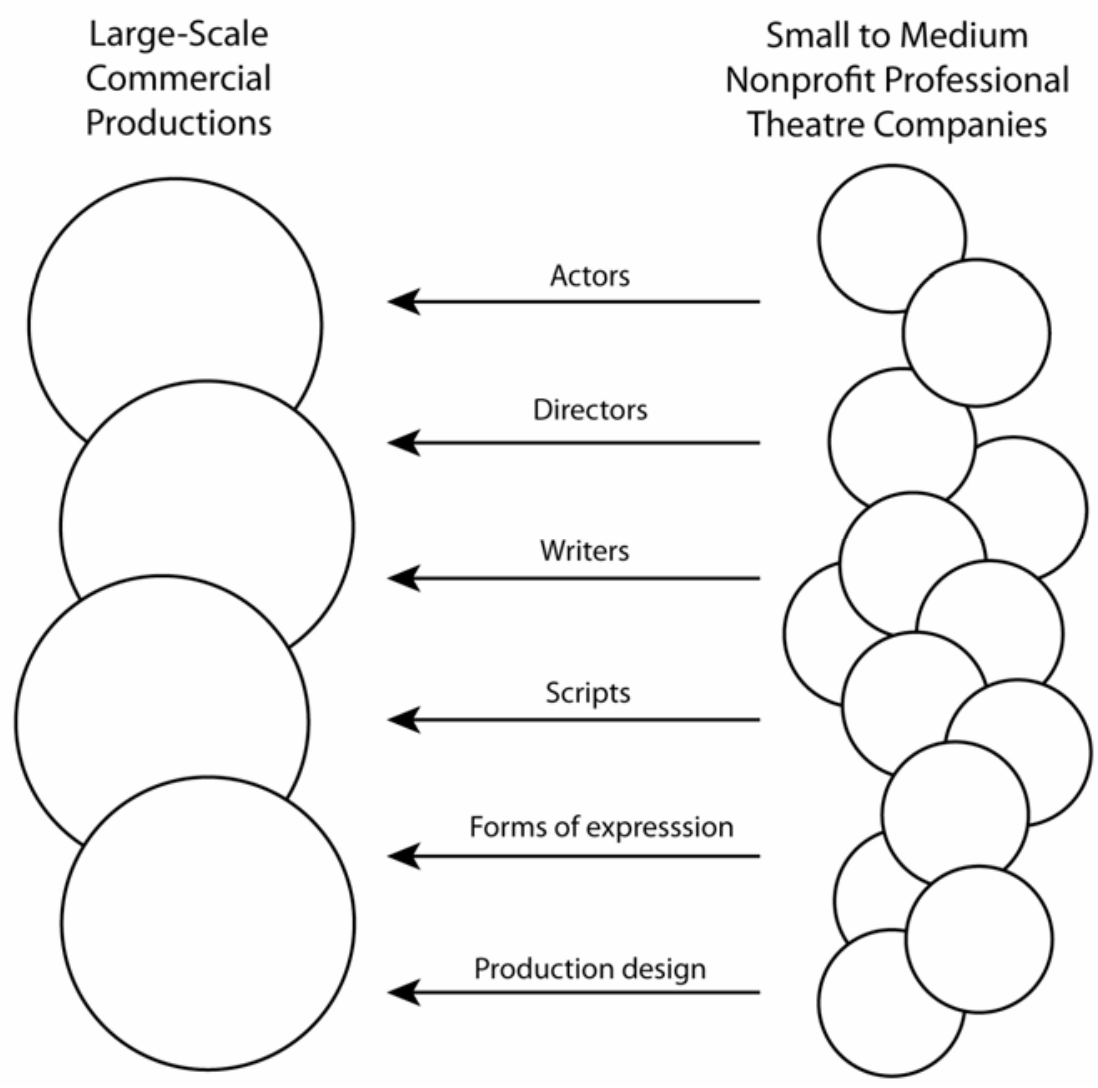

Fig. 1. Large commercial productions tend to take resources from small to medium nonprofit professional theatre companies

Small theatre companies provide a way for unknown actors and directors to enter the theatre world. When they become successful and are noticed, large productions hire them (even occasionally before the end of their current run) to perform or direct a large-scale production. Writers, in a similar fashion, will find that their scripts may soon be in demand on the commercial stage. Production design might be copied and forms of expression, for example ethnographic playscripts that were first performed on experimental stages have found their way to commercial productions. Two examples of this are the long-running and commercially successful musicals, Hair and A Chorus Line, which were originally developed Off-Broadway by The Public Theater.

We present this information in this way, because, a casual observer may see this transfer of resources occurring and think nothing of it. Perhaps they see movement from nonprofit to commercial venues as a career progression. However, there are more levels to reality than this somewhat superficial level. In many cases, there is some degree of a trading, mutually beneficial reality that needs to be explicitly identified.

If we adopt the use of the third space Bhabha, 1994) and Frenkel (2008), we are examining the relationship of the Broadway Theatres and the nonprofit professional 
theatres in the third space of mutually influential post-colonial exchanges. The use of the third space metaphor can help us understand more deeply the shaping that is going on between commercial Broadway productions and nonprofit professional theatres as they exchange ideas about the successful IT practices concerning scripts, actors, directors, forms of plays, and production design.

This paper uses the metaphor of colonialism to better understand the relationships between commercial theatre productions and small and medium nonprofit theatre companies. It is not a paper with a political mission to defend or subvert colonialism. Under no circumstances should this be considered a subaltern study or any other study about world politics. We only wish to say that colonialism is an appropriate metaphor for what happens in the business world and that, through a given lens, it is possible to see how IT can be used to be mutually beneficial to both large business and small and medium enterprises.

\section{The Beginnings of the Nonprofit Professional Theatre In and Out of New York}

Since the inception of the nonprofit professional theater, there has been a remarkable amount and variety of communication among large commercial productions and small and medium-sized nonprofit professional theatres. Small to medium-sized nonprofit, professional theatre can trace its origins to three or four key events and personalities, inside and outside of New York City, which proved to be the wellspring of inspiration for such theatres thereafter. Although we do not have space to recount all of the watershed artistic achievements during this period, the work of Conte and Langley (2007) is a recommended source. We are indebted to their insightful research in helping to inform and shape our view of this important era.

The beginning years span the decades from 1912 to the end of the 1940s, and they include the offering of an extremely influential playwriting class at Harvard University, the so-called defection of members of the New York Theatre Guild in New York to form the Group Theatre in 1929, the Federal Theatre Project which, along with its productions inspired the creation of the National Theatre Conference, and the establishment of important theatres and resident acting companies outside of New York such as the Cleveland Playhouse (1917); the Hedgerow Theatre of Philadelphia, established in 1923 by Jasper Deeter; the Playhouse Pittsburgh (1933); and the Barter Theatre, established by Robert Porterfield's in Abingdon, Virginia, also in 1933.

During this nascent period of 1912-1947, Conte and Langely (2007) describe the creation of the National Theatre Conference as "a collection of theatre people... who sought to reduce the dominance of commercial Broadway theatre and encourage artistically challenging work, not tied to the profit motive,"(p.115). Conte and Langely (2007) go on to summarize their observations by stating that " Much of the hope and passion engendered by the Federal Theatre Project activities (circa 1935-1939) seem to have taken root in the work of Margo Jones and her Theatre '47 in Texas, helping to inspire the subsequent proliferation of professional theatres outside of New York City. In 1947, Margo Jones' Theatre '47 was established in Texas and provided a prototype of a nonprofit organization, on which many new nonprofit theatres eventually would be based. (Conte and Langley, 2007, p. 115.) They further comment; "Jones 
combined the attributes of intelligence, professionalism, and dedication to artistic integrity that remain cornerstones of the majority of nonprofit theatres today," (p. 117).

The years from 1950 to 1960 in the US have been labeled as "the birth of the nonprofit theatre movement," (Conte and Langeley, p. 117). This was a time when productions Off-Broadway and Off-Off Broadway were created as a response to the rising production costs of putting on shows in commercial theatres. In 1954, Joseph Papp founded The Shakespeare Workshop, which later became known as The Public Theater (www.thepublictheater.org, 2009). The Public has since received countless awards and has transferred 52 shows from the non-profit arena to Broadway, including shows like $A$ Chorus Line and Hair.

According to Conte and Langely, the almost 600 million dollar commitment of the Ford Foundation in 1957 was a crystallizing moment that turned the budding urges toward artistic expressionism, realism, and escape from commercialism into the "nonprofit theatre movement." For the first time the funding agency mandated that in order to receive a philanthropic gift, theatres, along with other types of "respectable" performing arts such as dance and classical music, must operate as "an ongoing, nonprofit organization." In addition it had to exist as a professional entity "both in terms of its objectives and employees," (p. 117).

Other important theatre alliances sprung up to help support and nurture the new nonprofit movement network including the Theatre Communications group (TCG) in New York City. During this same period, the actors' union, Actors' Equity, recognized that demands on actors in nonprofit professional companies would be essentially different than demands on Broadway actors, and a group of managers from the larger nonprofit theatres formed the League of Resident Theatres (LORT), which now negotiates contracts with unions on the part of theatres who are its members (Conte and Langely, 2007, p. 118). In 1965 the National Endowment for the Arts (NEA) was created via federal legislation. Federal, state and local funding for the arts became a reality, however, nonprofits (and explicitly not commercial productions), were the only entities eligible to receive this funding. (Subsequently strategic nonprofit and commercial alliances successfully skirted this prohibition, but more of that in an upcoming section.)

\section{The Struggle for Artistic and Economic Freedom in Nonprofit Theatres}

Thus, for the last forty years or so, the nonprofit small to medium-sized professional theatres either Off-Broadway, Off-Off Broadway, or dotted throughout small and medium-sized cities in the US, have forged a post-colonial identity in rebellion against and response to, the colonizing commercial force of Broadway theatre. Strong impulses surrounding longing for freedom of two kinds propel the nonprofit theatre movement freedom. These impulses embrace artistic expression and eschew staggering and oppressive production costs. Whereas colonization of artistic endeavors often means a homogenization of narrative into one mainstream voice that can fail to represent the multiple perspectives of the American story and lapses into a mainstream story that satisfies the masses but not the individual or minority, the nonprofit professional theatres provide the articulation of diverse voices, narratives, and experiences. 
In this article we build on the metaphor of the third space created by Bhabha (1994) and successfully extended by Frenkel (2008). Although both were discussing knowledge transfer, we use their conceptualizations to specifically characterize and explore the transfer process of culture (and thereby best IT practices and good management lessons) to and from small and medium-sized nonprofit professional theaters to and from large, commercial theatre productions. We use the conceptual framework of Bhabha in understanding the dynamics of colonial and former colonies in a postcolonial relationship to critique and understand both the verbal (scripts, publications, marketing copy, and Web sites) and nonverbal discourse (i.e. tangible interchanges such as costumes, sets, actors, directors, and so on) as well as the combination of verbal and nonverbal acts that become known as a "production," including a script, direction, and so on used for cultural transmission between small performing arts organizations and large commercial productions.

\section{Defining the Third Space for Cultural Exchanges between Nonprofit Professional Theatres and Commercial Productions}

Bhabha (1994) and others are concerned with the "assumption that power relations between colonizer and colonized cannot be fully understood by focusing on the resources and structural forces that coerce the behavior of the dominated," (Peltonen, 2006, p. 530 as quoted in Frenkel, 2008). "Instead, power is seen as relational, emerging out of the mutual process of identity construction in both participants," (Frenkel, p. 926). Frenkel goes on to comment that Bhahha views knowledge as integral to the operation of power. So we see that the "formation of colonial knowledge" as emergent-being born of the "asymmetric and power-laden encounter between the colonizers and colonized, and as serving to naturalize and legitimize the colonizers' domination (Bhabha, 1994) as discussed in Frenkel (2008, p. 926).

Bhabha elaborates on the constructions of mimicry, hybridity, and the third space as they relate to the interactions of colonists and those being colonized. His comments illuminate a new way of seeing discourse between the colonized and the colonizer.

Bhabha (1994) states:

"The discourse of mimicry is constructed around an ambivalence; in order to be effective, mimicry must continually produce its slippage, its excess, its difference. The authority of that mode of colonial discourse that I have called mimicry is therefore stricken by indeterminacy; mimicry emerges as the representation of a difference that is itself a process of disavowal. Mimicry is, thus the sign of a double articulation: a complex strategy of reform, regulation and discipline, which 'appropriates' the Other as it visualizes power. Mimicry is also the sign of the inappropriate, however, a difference or recalcitrance which coheres the dominant strategic function of colonial power, intensifies surveillance, and possess an immanent threat to both 'normalized' knowledges and disciplinary powers." (pp. 122-123).

So colonial powers and the colonized might experience mimicry, and a state that Bhabha labels "hybridity" as well. In the case of hybridity, Bhabha departs from other colonial and post-colonial theorists. Frenkel (2008) reminds us, "In Bhabha's terms it 
is used to problematize the naturalized and ahistorical conceptualization of nationhood in general and of national culture in particular," (p. 926). Bhabha instead claims that, according to Frenkel, "nations and cultures must be understood as "narrative" constructions that arise out of the hybrid interaction of competing national and cultural constituencies," (p. 927). Frenkel continues her analysis by noting that, "proponents of Bhabhaian perspective would ask how the introduction of practices or technologies contributes to the reformulation of national identities and cultural beliefs," (p. 927.) Frenkel notes that Bhabha emphasizes that individual characteristics ... are subject to change and modification through experience, including the experience of coping with an imposed body of foreign knowledge," (pp. 927 \& 928).

\section{The Third Space}

In a liberating insight, that serves to free researchers and others from rigid interpretations of "essentialism" and "naturalization" (Frenkel, 2008) of what happens in the exchanges between colonizers and colonies, Bhabha comes forth with a creative construction of what he calls the "third space." In the metaphor of the "third space of inbetween," (Bhabha, 1996) we find that there are no absolutes, and certainly no absolutes that pre-destine the direction of influence. Frenkel continues her excellent description by stating," This space is not entirely governed by the laws of either ruler or ruled, and it is here that hybrid cultures are constructed that belong to neither of them but that are instead a fusion of the two," (p.928). She states, "From a Bhabhaiaian point of view, the third space is a liminal space in which the "cutting edge of translation and negotiation" between the colonizer and the colonized is to be found," (Bhabha, 1994, p. 38 as quoted in Frenkel, p. 928).

What is fascinating to us in this study is "the idea that the metaphor of the third space inspires us to think of the colonial encounter as a space of contradiction, repetition, ambiguity, and the disavowal of colonial authority and as a space that does not allow for authentic and essentialist oppositional polarities," (Frenkel, p. 928). She continues by saying that, "within this metaphoric space we construct our identities in relation to these varied and often contradictory systems of meaning," (p. 928).

Nonaka and Konno (1998) are business scholars who have effectively identified and described the concept of $b a$ drawn from Japanese philosophy, which might be usefully considered as somewhat akin to Bhabha's third space, "For those unfamiliar with the concept, $b a$ can be thought of as a share space for emerging relationships. This space can be physical (e.g. office, dispersed business space), virtual (e.g. e-mail, teleconference), mental (e.g., shared experiences, ideas, ideals,), or any combination of them. What differentiates $b a$ from ordinary human interaction is the concept of knowledge creation.... Thus, we consider $b a$ to be a shared space that serves as foundation for knowledge creation," (Nonaka and Konno, 1998, p. 40).

Nonaka $(1991 ; 2008)$ asserts that tacit knowledge resides in the individual and is evoked and evolved through individuals interactions. For Nonaka and Konno (1998) knowledge management is about humans and their relationships first, whereas IT for knowledge management is of secondary importance. Other researchers examining IT within small businesses have remarked on the importance of IT for maintaining the essence of small businesses, that is, their knowledge creation emanating from informal 
exchanges, "What surprised us in our research was how quickly internal transparency fell away and the need for an IS arose. This need translated into a requirement for the organizational IS to be used to maintain the informal cross-functional communication channels that used to be accomplished through face-to-face communication among top management, " (Street and Meister, 2004, p. 502). As noted in Pfughoeft, Ramamurthy, Soofi, Yasai-Ardekani, and Zahedi (2003), “...effective use of the Web (for small businesses) may lead to enhancement of interpersonal relationships," (p. 471.)

Perhaps the concept of $b a$ coupled with the third space is a useful way to think about knowledge creation early in the process. Nonaka and Konno (1998) write of four characteristics of $b a$ : originating $b a$ which represents socialization, interacting ba which represents externalization, exercising $b a$ which represents internalization, and cyber $b a$ which represents combination.

Interacting $b a$ is of special interest to us here, since it is the place for exchanges such as the ones we envision between nonprofit theatres and larger commercial productions. "Interacting $b a$ is the place where tacit knowledge is made explicit, thus it represents the externalization proves. Dialogue is key for such conversions' and the extensive use of metaphors is one of the conversion skills required." (p. 47).

Also of keen interest to us, because it seems to harbor the spirit of the third space is "cyber $b a$ " which is "a place of interaction in a virtual world instead of real space and time; and it represents the combination phased," (Nonaka and Konno , 1998, p. 47). They further describe cyber ba: "Here the combining of new explicit knowledge with existing knowledge generates and systematizes explicit knowledge throughout the organization." and "The use of on-line networks, group-ware, documentations, and database has been growing rapidly ...enhancing this conversion process," (p. 47).

While there are intriguing similarities between the third space and $b a$, two aspects are strikingly different. One is the collaboration which goes beyond sharing, adopting, and adapting of each other's best practices, moving to a relationship that is maintained and advanced by actively creating together as embodied in the larger concept of $b a$. The other is the identification of explicit tension in collaborative relationships (Nonaka, 2008, p.1) that is necessary for "real exchange."

For nonprofit theatres interacting with large commercial theatrical enterprises, collaborative knowledge creation certainly is an exciting prospect and holds out great promise. For some large and small theatres working together, knowledge creation is already taking place. Evidence of knowledge creation can be found in many joint productions in theatre and in opera, fostering of budding playwrights, and special "black box" theatrical creations that tap into what is being creating in $b a$. In addition, there is joint management of box offices, and there are joint promotional efforts that seek to boost the reputations of both for-profit productions and nonprofit theatres.

\section{Analyzing the IT and Culture Transfer Process}

In this section, we elaborate on our approach to analogize the work of Bhabha (1994), originally written to focus on "the distribution of knowledge and practices from the colonial metropole to the colonies - and the way that the distributed knowledge is assimilated and distorted as a reflection of the power relations between distributor and receiver," (Frenkel, 2008, p. 925), in order to examine, interpret, and understand how the 
dominated forces (small, and medium-sized professional, nonprofit theatres) are able to transmit culture to the dominant forces (in our case, large-scale commercial productions). This analysis is undertaken to better understand how IT and people transmit the culture (lessons learned, best practices) of small, professional, nonprofit theatres to large-scale commercial productions, to suggest best practices that can be learned by large-scale commercial productions, and to suggest future research directions.

Conte and Langely (2007) comment "The nonprofit theatre and the commercial theatre have become dependent on each other for growth. Nonprofit theatres depend on the revenues from transferring their productions to commercial venues, and Broadway and West End producers depend on new and fully developed products to produce. Despite criticism from both industries suggesting that commercial and nonprofit theatre should function independently, the combination of business models is more economically realistic and viable for both parties," (p. 119).

Some examples of cooperation between large-scale commercial productions and small to medium-sized nonprofit professional theatres are shown in the third space in Figure 2. These areas of collaboration include learning, the creation and nurturing of

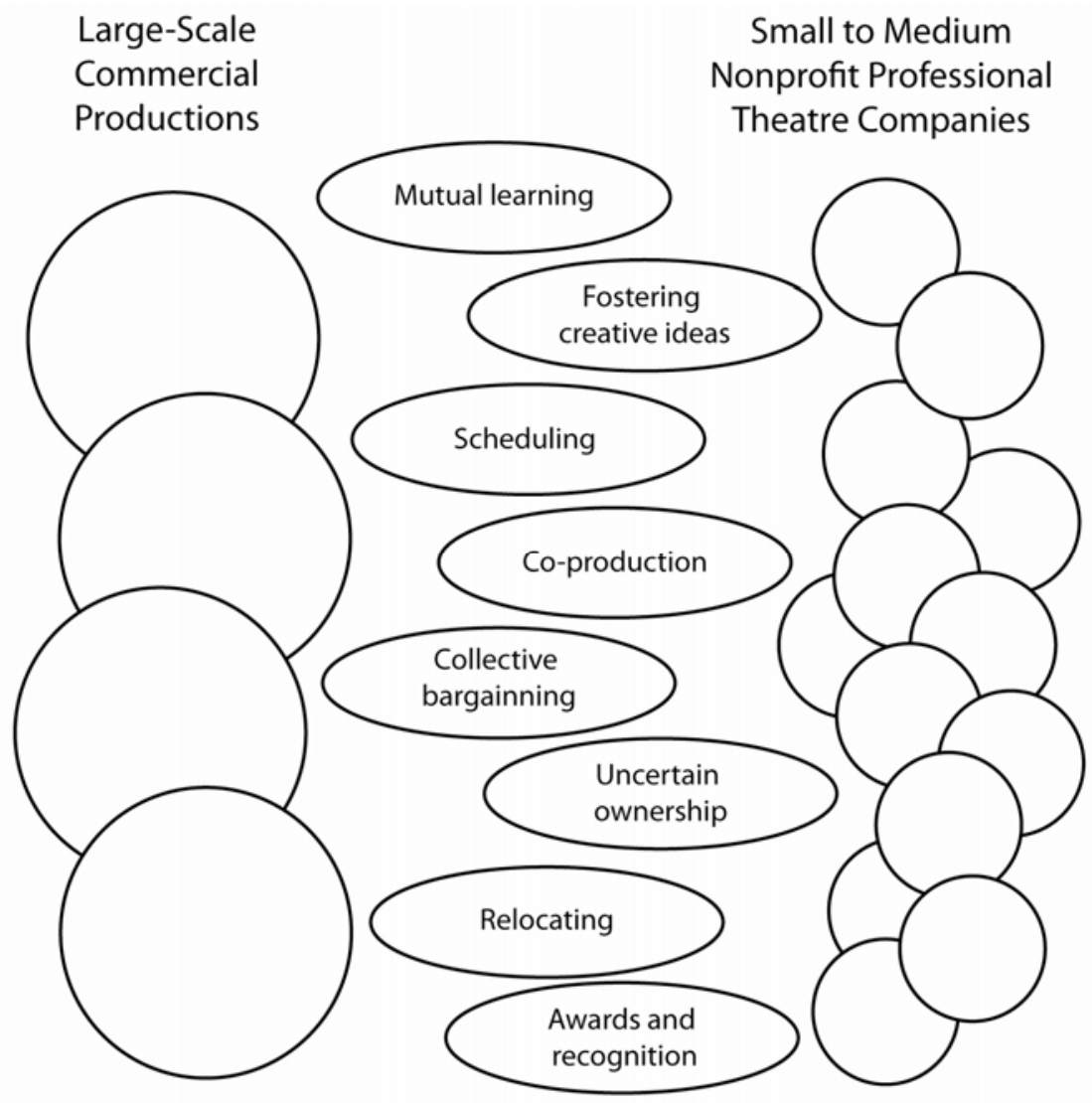

Fig. 2. In the "third space" cooperation and collaboration can result in mutually beneficial activities that can help and improve the theatre industry 
new ideas, and the art of scheduling productions. They also involve co-production, the relocation of a particular show, and a resolution to questions about ownership of the script or even production values.

Cooperation between commercial productions and nonprofit theatre companies may involve collective bargaining, where unions are able to recognize the risks and rewards of experimental, nonprofit theatre and their benefit to the theatre industry and to society as a whole. They can include shared values and agreement to participate in joint awards and recognition made possible by groups such as The Drama League and The Drama Desk, who evaluate and reward both commercial and nonprofit productions and the actors, directors, and crew that participate in either or both world.

In the following section we examine how information technology can be used in the third space to benefit both large-scale commercial productions and nonprofit theatre companies.

\section{Cooperation and Collaboration in the Third Space}

We can usefully examine the mutually beneficial exchanges that take place in the metaphorical third space between small and medium-sized professional nonprofit theatres and large-scale commercial productions. Recall that in the third space, there is much give and take between the colonizer and the colonized. There is a negotiated space that permits the emergent identities of those existing inside of it to take on sometimes surprisingly original shapes and dimensions, responding to each other, the old structure, and the newly emergent ways of doing things. The third space is dominated neither by the colonizer or the colonized. Emergent ways of thinking, speaking, and behaving are all in evidence here.

The use of IT in small to medium-sized theatres can improve the use of IT in large commercial productions in a number of ways. Commercial productions did not have the incentive to improve their IT, while the nonprofits did. Some nonprofits found it necessary to comply with reporting requirements mandated by government funding they had secured. Therefore, the IT systems had to be improved. In other cases, nonprofits needed to manage patron subscription databases. All needed to keep track of donors. Since commercial productions did not have government reporting requirements, a subscription audience, or charitable contributions, the incentives were not there to develop this part of the IT.

In some instances, nonprofit professional theatres have been able to surpass commercial productions saddled with legacy systems that required increasing amounts of maintenance just to keep them running. In addition, new technologies, including email applications and Web-based tools, afforded nonprofits the opportunity to adopt open source tools that leap-frogged over some commercial legacy systems and permitted them to take the upper hand in developing current content that met younger target audiences' expectations. Commercial productions rely on outsourcing and the IT provided by affiliations or parent groups. The 35 commercial physical Broadway theatres are owned by three organizations (The Shubert Organization, the Nederlander Producing Company of America, and the Jujamcyn Amusement Corporation). The Broadway productions rent the space from these established organizations. 
Large-Scale

Commercial

Productions
Small to Medium

Nonprofit Professional

Theatre Companies
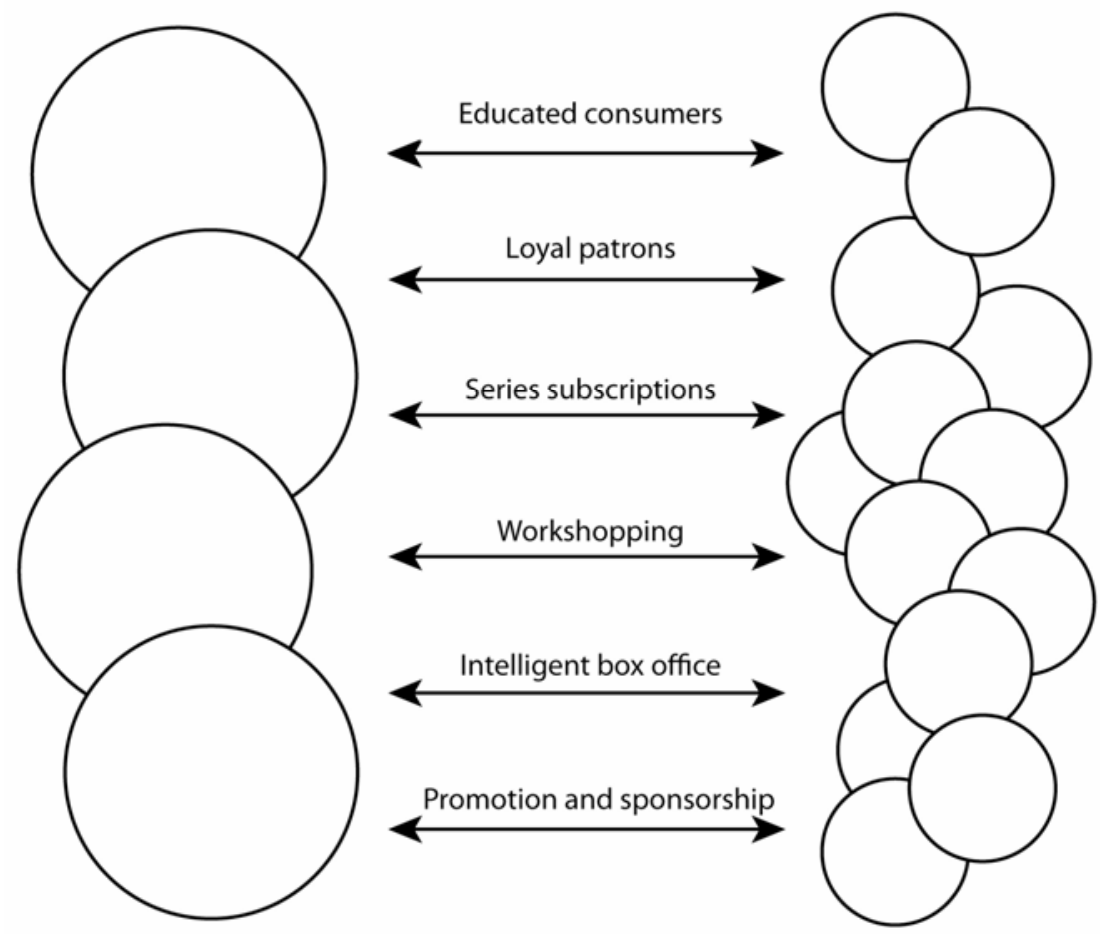

Fig. 3. Information technology can address the deliverables in the "third space" that are mutually beneficial to both large commercial productions and small to medium nonprofit professional theatre companies

Many nonprofit theatres might be classified as late adopters of information communication technologies (ICTs due to any number of reasons, which include the idea that priorities for funding went into productions not into IT, that there is a dearth of well-trained IT personnel available who will work at lower than industry-standard salaries; that there is a lack of budget for IT; that there exists a lack of a strategic plan for IT tied into a long term strategic plan for the organization's growth.

In the case of late IT adoptions of new tools, commercial productions existing in the third space learn the benefits of adopting newer, Web-based technologies; are influenced to catch up to the nonprofit theatres in the use of newer, IT-based media (rather than remain wedded to traditional print or television ads) to attract younger audiences accustomed to the Web, email, and social utility and networking Web sites including YouTube, Facebook, MySpace, Twitter, and many others.

In Figure 3 notice that there is mutual influence and exchange between large commercial productions and small to medium nonprofit professional theatre companies in 
the third space. It is our observation, based on our research with nonprofit professional theatres inside and outside of New York (Abuhamdieh, Kendall \& Kendall, 2002 \& 2007; Kendall, 2008; and Te'eni and Kendall, 2004) that there are at least six distinct deliverables that information technology can successfully address for largescale commercial productions as well as small to medium nonprofit professional theatre companies. These include educated audience members; loyal patrons, theatre series subscriptions, workshopping of original theatrical musicals and plays (Martin, 2007); the implementation and use of intelligent box offices, and promotion and sponsorship. (For a revealing picture formed by the mosaic of use of technology and nonprofits see the research articles in the volume edited by Cortés and Rafter, 2007.)

In the third space, IT serves as a cultural facilitator for theatres sharing information with each other. Information technology in and of itself also shapes the culture into new forms, and provides new ways of organizing and thinking about the enterprise that can inspire or unlock creativity and bring new perspectives to the fore. While this assertion is innovative in the context of small to medium-sized theatres exchanging ideas with commercial theatres, many IT researchers, particularly over the last two decades or so, have examined how information systems can facilitate the internal work of a variety of small businesses; how they can extend small business strategies to become competitive with large firms by employing their ICTs or examined the importance of developing information systems specifically tailored for small businesses (Cragg and King, 1993; Cragg and Zinatelli, 1995; DeLone, 1988; Harrison, Mykytyn and Riemenschnieder, 1997; Hussin, King, and Cragg, 2002; Iacovou, Benbasat, and Dexter, 1995; Levy, Powell, and Yetton, 2001; Raymond, 1985; Winston and Dologite, 2002; and Zinatelli, Cragg, and Cavaye, 1996.)

There are many ways in which IT supports the development of knowledge sharing and the transfer of knowledge between and among nonprofit theatres and commercial houses in the third space of Bhabha (2004) and in the cyber ba described by Nonaka and Konno (1998). This includes educating audience members; capturing and retaining loyal theatre patrons; developing theatre series for large scale theatre productions; using the Web as a workspace to post casting calls for workshop actors; collaborating on creative works and technical designs for workshops; implementing and using intelligent box offices to fully integrate services for audience members; partnering with each other to secure government grants for future collaborations; and creating strategic alliances and partnerships of commercial ventures and nonprofits to gain corporate sponsorships promoted on the Web and through the use of other ICTs.

For example, theatres can work to develop their own audiences from the theatregoing public by using IT to educate and shape audience members. They can also use their Web site to inform other theatres of the activities that are surrounding their artistic decisions. The building of interactive Web sites, complete with biographies of actors and directors featured in current productions, notes from the director, synopsis and analysis from a dramaturge, and costume sketches from the designer, can comprise a Web site that will enhance the exchange between the nonprofit and commercial theatres and actually help grow an audience that that becomes participants in the creative processes.

Commercial theatres in the third space can also learn from small and medium-sized nonprofit theatres about maintaining loyal patrons. Small theatres often effectively cultivate loyal patrons through building and maintaining individual relationships over 
the course of many theatre seasons. Small theatres often focus on retention rather than selling a seat to an anonymous customer anew every time a new show is mounted. Large commercial productions can learn form them to see customers as partners in a relationship. IT enters in when customer relationship management systems (CRM) are developed or purchased. CRM can be developed around the patron, rather than emphasizing a numbered seat in the theatre. This value is one that can be exchanged in the third space, since small nonprofit theatres often maintain excellent patron communications, and large commercial productions are very organized in their approach to the box office.

Other low-cost and effective ways to cultivate loyal patrons are popular with nonprofit groups who use IT to send push emails of upcoming shows, sending a monthly or quarterly newsletter via push email, including insider news, casting updates, and industry gossip. Push emails can also be used to tie into seasonal calendars that relay changes in performance times and dates due to holidays. Theatres can also use IT to send early notification of special events via email. While traditional "save the date" post cards for upcoming benefits might still be posted in regular mail, early notification of patrons permits theatres to facilitate two-way communication with their patrons and also get the word out ahead of a mailed invitation campaign.

Web sites can also serve as a standard IT platform for offering an array of interactive features that are meant to retain audiences, and also meant to keep them returning to the Web site to see what's new. Smaller sites put up by the nonprofit theatres allow audience member feedback, online booking, online contributions, seat selection, and support many other functions. Sites can be customized so that subscribers log in with a secure password, are addressed by name, and encounter other personalization features such as including a recommendation system that features other shows that may appeal to the subscriber. In addition, subscribers could then access specially tailored content (videos of current and past productions, interviews with artistic talent including designers and so on).

In the third space, larger commercial productions can learn from nonprofit professional theatres by creating Web spaces that are easy to navigate, fun to visit, and personalized. Since IT budgets for larger productions are often a grater portion of their capital expenditures, Web sites can be updated more frequently, and the sophistication and range of ICTs available increases.

Commercial productions exchanging ideas in the third space can teach small, professional nonprofit theatres a great deal about creative marketing tie-ins hosted on the Web site. Nonprofits can learn to offer scripts for sale, T-shirts, and other clothing with production logos as exciting ways to engage with the production of a play and also donate to the organization. In addition, small theatres can offer lists of nearby recommended restaurants, often featuring a discount on a meal or beverage.

Stickiness of a Web site should be a concern of every Web site developer. Subscribers and potential subscribers could be encouraged to remain on the Web site and interact via blogs, chat rooms, watching video clips of current and past productions. Reviews of the show from a variety of sources, including subscriber reviews can be hosted on the site so that patrons are encouraged to return to the site often.

Other examples of commercial productions interacting with nonprofit theatres in the third space include extending the concept of subscriptions facilitated by IT to include large-scale, commercial productions. Many nonprofit theatres rely on the sale of 
subscriptions for 60 to 90 percent of their revenue. Subscriptions are advertised on theatre Web sites and through emails. In addition, sale of subscriptions permits budget forecasts and planning for future seasons that other types of one-time sales do not permit. This ties in well to the building of customer relationships discussed in the previous paragraph, and it is a good use of IT for commercial productions as well. While nonprofit theatres may rely on paper and pencil audience surveys to get feedback about what audiences prefer to see, commercial productions can learn the importance of customer feedback in planning too, but will be able to use more costly data mining techniques to identify audience preferences and custom-build a series based on their findings of past show-goers.

Often commercial productions go through a well-defined workshopping process to evaluate material (often musicals Workshopping requires the hiring of actors and musicians, as well as a space to rehearse and present the workshop, all in a highly compressed time period. Sometimes the workshopping space is a rental space the theatre owns or it can be an actual black box theatre that is used for development purposes. Information technology enters the picture because of the extensive and fast-paced collaborative effort required to workshop a show. Typically professional actors are cast for the parts (although often they will not be those who ultimately wind up with the roles) but their qualifications must be submitted and reviewed. Pushing those tasks to a workspace on the Web would be effective. Also, creating passworded workspace on the theatre's Web site for collaborating on music, scripts, and technical designs would satisfy the desire for intense, time driven-collaborations with people from all over the world. Nonprofit theatres can benefit from collaborating on the Web with commercial productions for workshopping new material.

In the third space, commercial productions and nonprofit theatres can learn from each other about the importance of the data that is collected and distributed by the box office. Small, nonprofit theatres, often seem to instinctually recognize that data from the box office is the lifeblood for not only generating revenues but for contact with audience members. If a theatre is outsourcing their box office (this can happened with either type of theatre), they still need to learn to capture and analyze the data being generated. IT can inform this process in powerful ways. These include tracking of patrons, and storing then honoring their seating preferences (including days of the week and performance times). Some patron programs use people in the role of directors of individual giving to perform these functions, but with a large subscriber base, the software is a necessity.

Theatres can also push emails to patrons notifying of them when it is permissible to book a show that is part of their theatre series. This serves as a welcome reminder, and also maintains a relationship with the patron. In more sophisticated application, intelligent agents can be used to search the Web for new commercial productions that fit an audience member's established and stored profile. Currently, these agents are somewhat clumsy, often organized around stored data that the audience member visits New York or some other city frequently, and so pushes shows opening in New York. Other times, the push email will be based on the patron's ticket purchase history, building a little bit of a profile from sales of previous show tickets; e.g. you just saw Guys and Dolls, you will enjoy another revival that is opening on Broadway, Hair: The American tribal love-rock musical. Although these shows have different producers, cooperation benefits the entire industry (Kendall, 2008). 


\section{Educated audience members}

- Via Web sites, by providing playwright and actor bios, director notes, etc.

- Interactive Performance Calendars

- Open source content management systems

- Streaming video of former or current productions

\section{Loyal patrons}

- Customer relationship management (CRM) systems

- Push emails of upcoming productions, insider news, casting updates

- Push performance calendars around public holidays to show new performance times and changed performance dates

- Notification of special events via email

\section{Theatre series subscriptions}

- Extending the concept of subscriptions to include largescale productions

- Building a long term relationship with audience members

- Using data mining to custom build subscription series

\section{Workshopping of original theatrical musicals and plays}

- Advertising for actors for workshops

- Notice of workshop electronically

- Use of Web space for collaborating on music, scripts, and technical designs

\section{Implementation and use of intelligent box offices}

- Tracking of patrons, their seating preferences including days of the week and performance times

- Push notification to patrons when productions open for booking

- Using intelligent agents to search for new commercial productions that fit an audience member's profile

- Using patron's history to build profile

\section{Promotion and sponsorship}

- Cooperatively promoting enthusiasm for all theatre

- Creating strategic alliances and partnerships of commercial ventures and nonprofits to gain corporate sponsorship

Fig. 4. Specific functions IT can perform in the third space involing both large-scale commercial productions and nonprofit theatre companies

Finally, nonprofit theatres and commercial productions in the third space can benefit from participating in promotion. Organizations such as The Drama League, which predates by 12 years the Broadway-only Tony Awards, and The Drama Desk, include both nonprofit theatres and commercial Broadway productions when they bestow 
their annual awards. Web sites that function as information aggregators such as playbill.com, theatermania.com, and nytheatre.com do a satisfactory job of posting listings, reviews, interviews, and so on, but aggregators do not facilitate or encourage cooperation, they merely collect and display information. Commercial productions and nonprofits need to figure out ways to cooperate more using the Web.

Lastly, nonprofits and commercial ventures are working together in the third space to gain corporate sponsorship in order to fund innovative, socially conscious work in a larger venue, where all three work to form strategic alliances. The examples listed in Figure 4 summarize the foregoing specific instances of nonprofit theatres and commercial productions exchanging ideas and in turn being influenced in the third space.

\section{Suggested Future Research Directions}

There are many avenues of future research that can produce a lively dialectic and some very good ideas about transfer of IT and strategic management knowledge among and between theatres and productions of all sizes and financial status, whether commercial or not-for-profit. For example, it would be interesting to take a Bhabhaian perspective on Broadway theatre, examining it as postcolonial entity while examining the West End of London as the Colonial power, while assessing whether the metaphor of the third space is useful in understanding the dynamic interchange of ICTS, actors, directors, and productions that have become a hallmark of the US-British relationship over the last 40 years.

In the future, it would also be worthwhile to further elaborate and explore the interrelationship of the third space and $b a$, and to be able to identify where the two intersect and depart and what the meaning of those intersections and departures are for commercial productions and nonprofit theatres and their use of information technology.

\section{Conclusion}

In this article we examine the metaphor of the third space as proposed by Bhabha (1994), as a way to critique the discourse (both verbal and nonverbal) that encompasses IT, strategic management, and other exchanges between small and mediumsized nonprofit professional theatres symbolized by Off-Broadway and Off-Off Broadway theatres, and productions in London's Fringe, versus the large, commercial productions symbolized by Broadway and those in London's West End. Our motivation for this analysis is to deepen our understanding of the relationship of SMEs to large organizations, and to suggest that the mutual exchange of culture, including IT and other management practices from small theatres to large productions is usefully understood from a Bhabhaian perspective, with large, commercial productions learning from small and medium sized nonprofit theatres as well as the reverse, in what Bhabha envisions as the third space.

\section{References}

Abuhamdieh, A., Kendall, J.E., Kendall, K.E.: An Evaluation of the Web Presence of a Nonprofit Organization: Using the Balanced Scorecard Approach in Ecommerce. In: Traunmüller, R. (ed.) Information Systems: The E-Business Challenge, pp. 210-222. Kluwer Academic Publishers, Boston (2002) 
Abuhamdieh, A., Kendall, J.E., Kendall, K.E.: E-commerce Opportunities in the Nonprofit Sector: The Case of New York Theatre Group. International Journal of Cases on Electronic Commerce 3(1), 29-48 (2007)

Bhabha, H.K.: The Location of Culture. Routledge Classics, New York (1994) (originally published 1994, reprinted 2008)

Bhabha, H.K.: Cultures in between. In: Hall, S., du Gay, P. (eds.) Questions of cultural identity, pp. 53-60. Sage, Thousand Oaks (1996)

Conte, D.M., Langley, S.: Theatre Management: Producing and Managing the Performing Arts. Entertainment Pro., and imprint of Quite Specific Media Group, Ltd., Hollywood, CA (2007)

Cortés, M., Rafter, K.M.: Nonprofits \& Technology. Lyceum Books, Inc, Chicago (2007)

Cragg, P.B., King, M.: Small-Firm Computing: Motivators and Inhibitors. MIS Quarterly 17(1), 47-60 (1993)

Cragg, P.B., Zinatelli, N.: The Evolution of information Systems in Small Firms. Information \& Management 29(1), 108 (1995)

DeLone, W.H.: Determinants of Success for Computer Usage in Small Business. MIS Quarterly 12(1), 51-61 (1988)

Frenkel, M.: The Multinational Corporation as a Third Space: Rethinking International Management Discourse on Knowledge Transfer Through Homi Bhaba. The Academy of Management Review 33(4), 924-942 (2008)

Harrison, D.A., Mykytyn Jr., P.P., Rimenschneider, C.K.: Executive Decisions About the Adoption of Information Technology in Small Business: Theory and Empirical Tests. Information Systems Research 9(2), 171-195 (1997)

Helgesen, S.: The Practical Wisdom of Ikujiro Nonaka, strategy+business (Winter), http: / /www. strategy-business.com/press/article/08407 ?gko=31376 (last accessed, March 5, 2009)

Hussin, H., King, M., Cragg, P.: IT Alignment in Small Firms. European Journal of Information Systems 11(2), 108-127 (2002)

Iacovou, C.L., Benbasat, I., Dexter, A.S.: Electronic Data Interchange and Small Organizations: Adoption and Impact of Technology. MIS Quarterly 19(4), 465-485 (1995)

Kendall, J.: Metaphors for E-Collaboration: A Study of Nonprofit Theatre Web Presence. In: Kock, N. (ed.) E-Collaboration in Modern Organizations: Initiating and Managing Distributed Projects, pp. 14-30. Information Science Reference, Hershey (2008)

Kendall, K.E., Kendall, J.E., Lee, K.C.: Understanding Disaster Recovery Planning through a Theatre Metaphor: Rehearsing for a Show that Might Never Open. Communications of AIS 16, 1001-1012 (2005)

Levy, M., Powell, P., Yetton, P.: SMEs: Aligning IS and the Strategic Context. Journal of Information Technology 16, 133-144 (2001)

Martin, J.S.J.: A Jesuit Off-Broadway. Loyola Press, Chicago (2007)

Nonaka, I.: The Knowledge-Creating Company. Harvard Business Review 69, 96-104 (1991)

Nonaka, I., Konno, N.: The Concept of "Ba": Building a Foundation for Knowledge Creation. California Management Review 40(3), 40-54 (1998)

Peltonen, T.: Critical theoretical perspectives on international human resource management. In: Stahl, G.K., Bjorkman, I. (eds.) Handbook of Research in International Human Resource Management, pp. 523-535. Edward Elgar, Cheltenham (2006)

Pflughoeft, K.A., Ramamurthy, K., Soofi, E.S., Yasai-Ardekani, M., Zahedi, F.: Multiple Conceptualizations of Small Business Web Use and Benefit. Decision Sciences 34(3), 467-512 (Summer 2003) 
Raymond, L.: Organizational characteristics and MIS Success in the Context of Small Business. MIS Quarterly 9(1), 37-52 (1985)

Street, C.T., Meister, D.B.: Small Business Growth and Internal Transparency: The Role of Information Systems. MIS Quarterly 28(3), 473-506 (2004)

Te'eni, D., Kendall, J.E.: Internet Commerce and Fundraising. In: Young, D.R. (ed.) Effective Economic Decision-Making by Nonprofit Organizations, The Foundation Center, New York, NY, pp. 167-189 (2004)

Volz, J.: How to Run a Theater. Back Stage Books, New York (2004)

Webb, D.M.: Running Theaters: Best Practices for Leaders and Managers. Allworth Press, New York (2004)

Winston, E.R., Dologite, D.: How Does Attitude Impact IT Implementation: A Study of Small Business Owners. Journal of End User Computing 14(2), 16-29 (2002)

Zinatelli, N., Cragg, P.B., Cavaye, A.L.M.: End User Computing Sophistication and Success in Small Firms. European Journal of Information Systems 5(3), 172-181 (1996) 